Article

\title{
Implementation of a Demand-Side Management Solution for South Korea's Demand Response Program
}

\author{
Wonsuk Ko ${ }^{1}$ (1) , Hamsakutty Vettikalladi ${ }^{1}$, Seung-Ho Song ${ }^{2, *}$ and Hyeong-Jin Choi ${ }^{3}$ \\ 1 Department of Electrical Engineering, College of Engineering, King Saud University, \\ Riyadh 11421, Saudi Arabia; wkoh@ksu.edu.sa (W.K.); hvettikalladi@ksu.edu.sa (H.V.) \\ 2 Department of Electrical Engineering, Kwangwoon University, Seoul 01897, Korea \\ 3 Department of Electrical Engineering, Kwangwoon University \& GS E\&C Corp, Seoul 01897, Korea; \\ hjchoi@gsenc.com \\ * Correspondence: ssh@kw.ac.kr; Tel.: +82-2-940-5762; Fax: +82-2-940-5096
}

Received: 31 December 2019; Accepted: 26 February 2020; Published: 4 March 2020

\begin{abstract}
In this paper, we show the development of a demand-side management solution (DSMS) for demand response (DR) aggregator and actual demand response operation cases in South Korea. To show an experience, Korea's demand response market outline, functions of DSMS, real contracted capacity, and payment between consumer and load aggregator and DR operation cases are revealed. The DSMS computes the customer baseline load (CBL), relative root mean squared error (RRMSE), and payments of the customers in real time. The case of $10 \mathrm{MW}$ contracted customers shows $108.03 \%$ delivery rate and a benefit of 854,900,394 KRW for two years. The results illustrate that an integrated demand-side management solution contributes by participating in a DR market and gives a benefit and satisfaction to the consumer.
\end{abstract}

Keywords: demand response; demand-side management solution; electricity market; energy management

\section{Introduction}

In a power system, electricity demand changes constantly. Power suppliers need to generate more power generation when demand is high, and less when demand is low. Traditionally, to coordinate supply and demand has been the supplier's responsibility and the demand side has been considered secondary. The power system supplier predicts the demand and, then, generates the supply capacity to meet the demand. After that, market price changed to supply capacity serves as criteria for deciding the facility capacity. The capacity that cannot be adjusted on the supply side is supplemented by DSM (demand-side management) such as temporarily reducing or moving the load on the demand side [1,2].

Recently, there has been a growing interest in considering the demand as the same as the supply side. Technological changes are occurring both on the supply side and on the demand side. Demand response is an alternative to additional infrastructure to maintain the safe margin between generation or distribution capacity and demand. The definition of demand response from the United State Department of Energy says, "Changes in electric usage by end-use customers from their normal consumption patterns in response to changes in the price of electricity over time, or to incentive payments designed to induce lower electricity use at times of high wholesale market prices or when system reliability is jeopardized" [3]. The most significant technological change on the demand side is the spread of smart meters and advanced metering infrastructure. According to this environment, traditional DSM programs should redesign to an automated market-based mechanism. The responses from the demand-side resources should also be reliable, fast, flexible, and large enough to compete 
with the supply-side resources. DSM programs can be classified into load management (LM) types and energy efficiency (EE) types [4-8].

In order to deal with peak load conditions, electric utilities have to invest in system capacity, which is underutilized during most times. Not surprisingly, utilities have been seeking methods to improve capacity utilization. Demand response (DR) is one mechanism utilities use to curtail or shift peak customer load [9-11].

Regarding the remuneration, a price-based and an incentive-based DR program are used. In a price-based DR program, consumers reduce their power consumption by responding to the electricity tariff set by the electricity market. In an incentive-based DR program, consumers are contracted by individuals or groups to reduce their power consumption for a certain period that the economic transactions requested in the electricity market.

For a price-based DR program, researchers investigated a multi-agent modeling and optimization algorithms under DR programs for real-time prices [12]; a coordination strategy between a micro network and a price-based demand response program for adjusting loads [13]; a bidirectional communication smart meter design between the household smart meters and the distribution management system [14]; a dynamic price scheme for electricity in a smart network, by analyzing the behavior and the possible demand response of the consumer [15]; and a modified real-time price model that encourages customer choice in electricity rates and is based on the amount of risk customers are willing to take and a real-time grid condition index developed by the California Independent Service Operator [16].

For an incentive-based DR program, research has shown that a fuzzy-based dynamic incentive scheme for residential customers can effectively incorporate the influences of socioeconomic conditions, expected curtailment, probability of curtailment, and notice period [17]. The dynamic adjustment of the offered prices is analyzed to reduce the demand and maximize its performance within T days [18]. The uncertainty of the demand in the network planning is modeled and includes the integral control of the load disconnection in search of the minimum cost [19]. The participation of smart homes with the help of a controller is capable of managing the electrical installation and restructuring the demand profile by changing the operation of the flexible loads [20]. The incentives motivate clients to participate in automatic DR programs with the purpose of compensating imbalances between offer and demand [21], and a DR program is shown from the economic point of view based on optimal incentives [22].

Demand resources have played an important role in Korea for more than 20 years. To reduce peak demand during summer and winter, DR programs and the operating system have been researched and implemented as a demonstration since 2010. In 2014, any customers who joined the DR market were able to sell their reduced demand in the electricity market as supply resources $[23,24]$.

In this paper, a development and case studies of demand-side management solution (DSMS) in South Korea is presented. After that, the DSMS is verified with a one-year experience of the Korea DR program. To implement this solution, a design structure of the DSMS is proposed and tested. Customer baseline load (CBL), relative root mean squared error (RRMSE), load curtailment value, and money-saving of contracted customer's data are also displayed from the DSMS. To calculate CBL, a short historical period close to the event day was chosen, then, the CBL was calculated by merely averaging the data of the previous not-event days. After deciding the CBL, the assessment of the estimated CBL is needed. In order to verify the accuracy of the calculated CBL, RRMSE is used to assess the estimation error by comparing the actual electricity load and the estimated CBL. If the estimation error is close to zero, it means there is the high accuracy of the estimated CBL; if it is greater than zero, it means overestimated CBL; and if it is less than zero, it means underestimated CBL [25]. The calculation process of CB L and RRMSE are explained in Section 2.

This paper is composed as follows: Section 2 shows Materials (status of demand resource market in South Korea) and Methods (development of DSMS); Section 3 presents the money savings and energy conservation results using DSMS; finally, the discussion and conclusions are given in Sections 4 and 5. 


\section{Materials and Methods}

\subsection{Status of Demand Resources Market, South Korea}

The role of the Korea Power Exchange (KPX) is to control the operation of South Korea's electricity market and the power system, as well as execute real-time dispatch and establish the basic plan for supply and demand. Every year, the KPX has issued an annual report for the electricity market trend and analysis. In this section, the status of the demand resource market from the 2016 annual report is summarized. Demand response refers to a suite of policies and institutions to provide efficient and stable electric power service at the lowest cost by helping consumers change their consumption pattern. Under the current contract-based utility rate schemes in South Korea, consumers have a very weak incentive to voluntarily participate in the demand response [26].

The introduction of the demand response program can effectively stabilize the electricity market and the operation of its system. The demand response can decrease investment in the power system including generation, transmission, and transformation networks; enhancing reliability in electric-power supply. Consumers can take part in the demand response programs by reducing their electricity usage at critical times through monitoring demand or securing a load that can be shut down by KPX and then making a bid on a load.

In early 2008, when the demand response market opened, it was bidding-based sponsored by the Electricity Industry Fund and, now, is making a transition into an advanced demand response market where market price and real-time system operation are linked with each other for resource transaction. In 2012, a smart demand response market opened where demand resources in small and medium quantity were traded in an effort to tap into the highly reliable and easily accessible demand resources using smart grid technology. The smart demand response market makes payment at a fixed rate on the condition of keeping the capacity to be curtailed unchanged. A payment is also made to those who cut down demand at the system operator's request for load curtailment. As the Electricity Business Act was revised to allow demand resource trading in the electricity market, in 2014, the demand response market and smart demand response market sponsored by the Electricity Industry Fund were abolished in late 2014, and the elimination of the two-month-ahead and week-ahead programs followed in late 2015 [26].

At the end of 2015, a new demand response market replaced these previous programs and was integrated into the electricity market. Figure 1 shows the process of the trading mechanism of a demand response market. The demand response market trades demand resources arranged by retailers, each demand resource is required to come from more than ten end users, and must be valued at above 10 MW. The DR aggregator collects consumers to organize demand resources. After registering with $\mathrm{KPX}$, these resources are certified for trading under the same rules governing the centrally dispatched generators. Demand resources are put on a bid against power generation resources on a daily basis, and when sold, demand curtailment begins. In the system operation process, consumers are required to cut down on demand within an hour of a dispatch order.

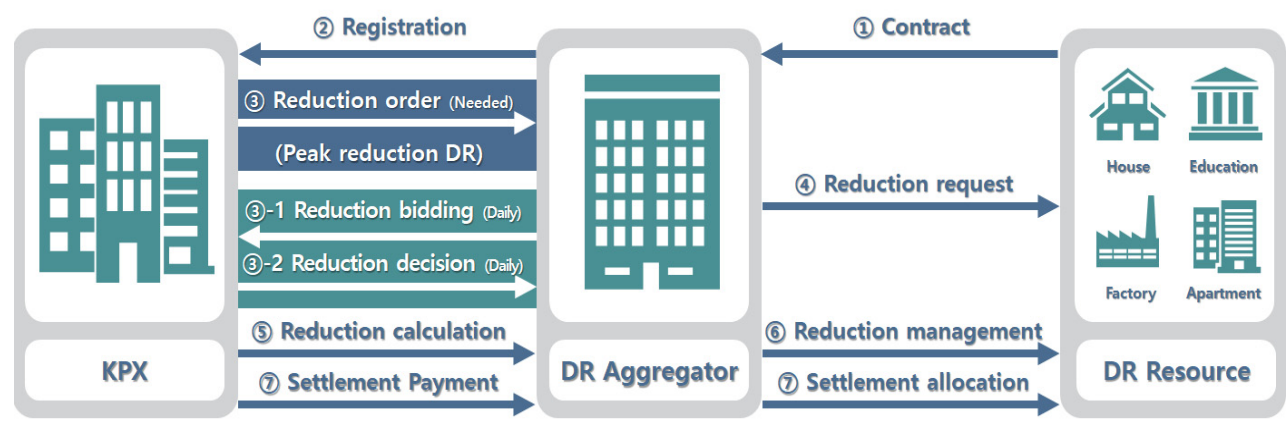

Figure 1. Trading mechanism of a demand response market. 
The KPX calculates curtailed energy and makes payment to retailers who allocate the profits to consumers. As indicated in Tables 1 and 2, the demand response market has seen significant progress from both quantity and quality perspectives. The number of consumers has grown from 90 to 3592 and curtailed energy amounts to $175,771 \mathrm{MWh}$, up by 342.6 times from $513 \mathrm{MWh}$, becoming a world-renowned global demand response market. The transition to an advanced demand response market is also politically compelling. As the program matures along with demand resources integrated into the electricity market, market participants will feel easy to understand the system and the market will flourish. Furthermore, lower resistance towards generators and greenhouse gases are expected along with eased market exploitation and a more efficient market [23].

Table 1. Consumers and curtailed power before market opening [23].

\begin{tabular}{cccccc}
\hline Year & $\mathbf{2 0 1 0}$ & $\mathbf{2 0 1 1}$ & $\mathbf{2 0 1 2}$ & $\mathbf{2 0 1 3}$ & $\mathbf{2 0 1 4}$ \\
\hline No. of consumers & 90 & 119 & 158 & 159 & 159 \\
\hline Capacity available for curtailment (MW) & 2219 & 3049 & 3612 & 3615 & 3615 \\
\hline Curtailed energy (MWh) & 513 & 690 & 785 & 556 & 682 \\
\hline
\end{tabular}

Table 2. Consumers and curtailed power after market opening (provided by KPX, July 2018).

\begin{tabular}{ccccccccc}
\hline Year & $\mathbf{2 0 1 4 . 1 2}$ & $\mathbf{2 0 1 5 . 0 6 \sim}$ & $\mathbf{2 0 1 5 . 1 2}$ & $\mathbf{2 0 1 6 . 0 6}$ & $\mathbf{2 0 1 6 . 1 2} \sim$ & $\mathbf{2 0 1 7 . 0 6} \sim$ & $\mathbf{2 0 1 7 . 1 2}$ & $\mathbf{2 0 1 8 . 0 6 \sim}$ \\
$\mathbf{2 0 1 5 . 0 5}$ & $\mathbf{2 0 1 5 . 1 1}$ & $\mathbf{2 0 1 6 . 0 5}$ & $\mathbf{2 0 1 6 . 1 1}$ & $\mathbf{2 0 1 7 . 0 5}$ & $\mathbf{2 0 1 7 . 1 1}$ & $\mathbf{2 0 1 8 . 0 5}$ & $\mathbf{2 0 1 8 . 1 1}$ \\
\hline No. of DR aggregators & 11 & 15 & 14 & 15 & 14 & 17 & 20 & 22 \\
\hline No. of consumers & 861 & 1323 & 1519 & 1970 & 2223 & 3195 & 3580 & 3592 \\
\hline $\begin{array}{c}\text { Capacity available for } \\
\text { Curtailment (MW) }\end{array}$ & 1520 & 2444 & 2889 & 3272 & 3885 & 4352 & 4271 & 4222 \\
\hline $\begin{array}{c}\text { Curtailed energy } \\
\text { (MWh) }\end{array}$ & 117,075 & 91,034 & 98,898 & 293,955 & 113,661 & 62,110 & 121,206 & - \\
\hline
\end{tabular}

\subsection{Development of Demand-Side Management Solution (DSMS)}

To realize the trading mechanism of a demand response market, as shown in Figure 1, the structure of a demand-side management solution is designed, as shown in Figure 2. The DSMS directly captures usage data by sensor every $5 \mathrm{~min}$ from demand resources such as a house, building, apartment, and factory. After that, these usage data are sent to the KPX server every $5 \mathrm{~min}$. If a power shortage occurs, the KPX sends a reduction order to the DSMS. When the request is generated from KPX, the DSMS calculates the CBL of the DR duration time and, then, contacts the DR resources to request the contracted power reduction amount, and after that, demand curtailment begins. In the system operation process, consumers are required to cut down on demand within an hour of the dispatch order. The DSMS also calculates the RRMSE (relative root mean square error), the CBL (customer baseline load) of the DR resources, regularly to keep the DR resources in the Korea electricity market.

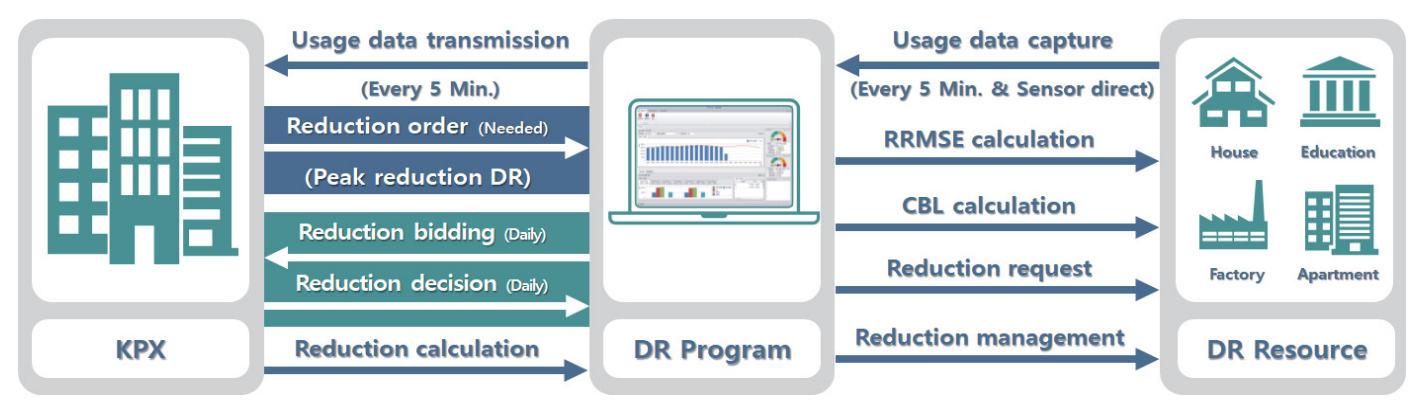

Figure 2. The structure of a demand-side management solution. 
The CBL is the prediction of the amount of electricity that would generally be used if electricity consumption had not been reduced by the KPX directive [27]. Figure 3 shows the power consumption and CBL of the desired date and time. The bar graph illustrates power usage at $5 \mathrm{~min}, 10 \mathrm{~min}$, and $30 \mathrm{~min}$, respectively and the line means the CBL of every hour. At the bottom, the dialog box shows contracted curtail power, CBL, load, result of curtailed power, and remained contracted curtail power in order.

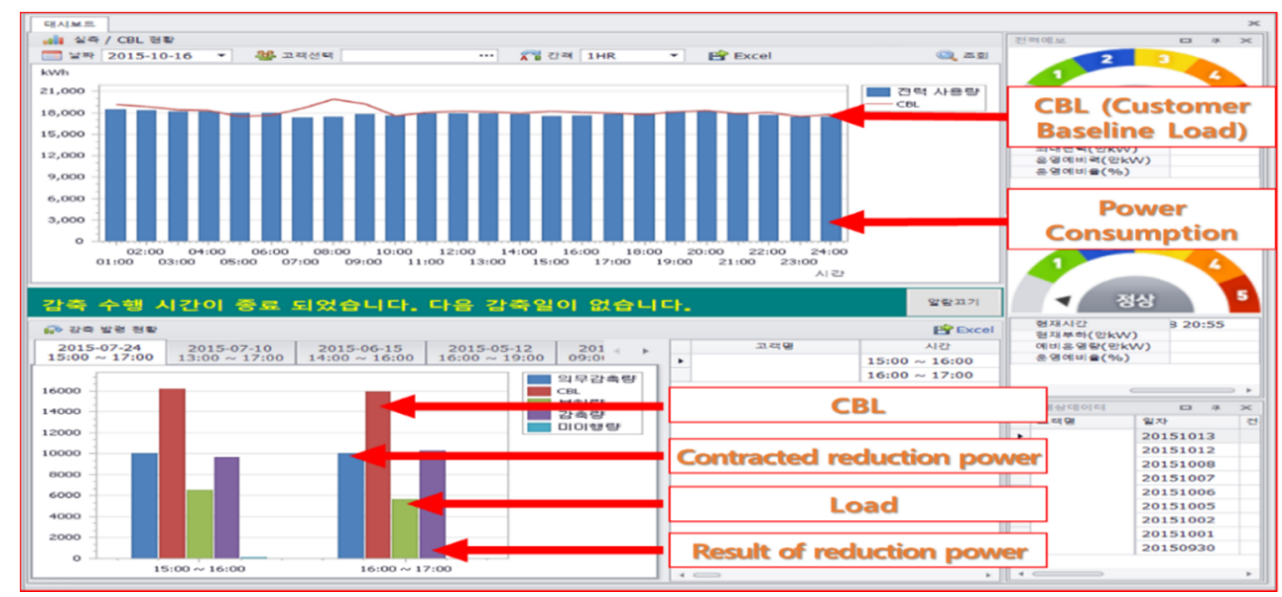

Figure 3. Dashboard of power usage.

Figure 4 illustrates a customer baseline load (CBL) calculation. The CBL is an average hourly energy consumption calculated as follows: According to the KPX guideline, the CBL calculation method is either MAX 4/5 or Mid 6/10. The Max 4/5 method is calculated using the electricity usage in normal working for 5 consecutive days. To calculate the CBL, first, the smallest electricity usage day of the 5 days is excluded, then, the average usage for 4 days is used as Max 4/5 CBL. The Mid 6/10 method is calculated based on the power electricity usage in normal working for 10 consecutive days. Two days are excluded from the top and bottom usage of the 10 days, respectively. The average usage of the remaining six days is used as Mid 6/10 CBL. Table 3 explains how to calculate the CBL as MAX $4 / 5$. First, D-2 is the smallest electricity usage day, therefore, this day is excluded. Then, the average usages of the remained 4 days are added, and then divide by 4 [27].

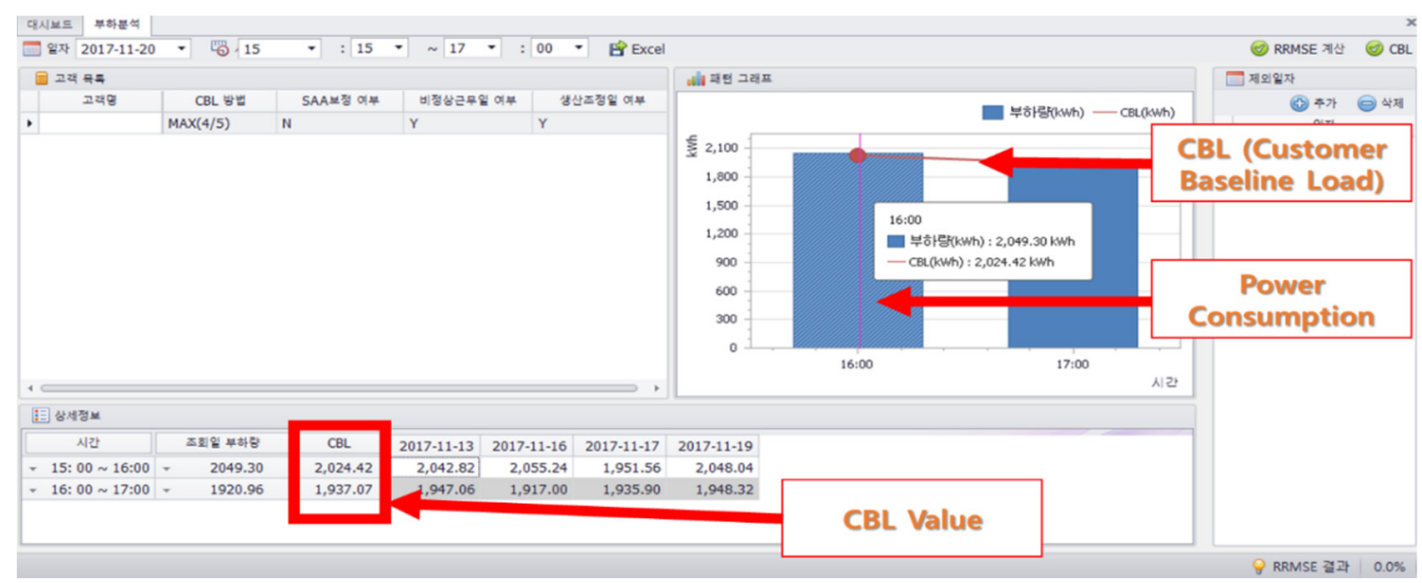

Figure 4. Customer baseline load calculation. 
Table 3. Calculation example of the customer baseline load (CBL) (Max4/5 Method).

\begin{tabular}{ccc}
\hline & Energy Consumed (kWh) & Selection \\
\hline D-1 & 2048.04 & $\mathrm{O}$ \\
\hline D-2 & 1889.74 & $\mathrm{X}$ \\
\hline D-3 & 1951.56 & $\mathrm{O}$ \\
\hline D-4 & 2055.24 & $\mathrm{O}$ \\
\hline D-5 & 2042.82 & $\mathrm{O}$ \\
\hline CBL & Average of selection value $=2024.42$ \\
\hline
\end{tabular}

To estimate the DR reduction value, the pattern of regular power use should be fairly uniform, and an objective evaluation technique is required. For this objective evaluation, the RRMSE was used as an index to specify the uniformity of the pattern of power usage. Figure 5 shows the RRMSE for the customer who wants to participate in demand response market and Equation (1) shows that RRMSE calculation [26]. In this equation, $D$ is an investigation day, $D(n)$ is the number of investigation days, $T$ is a time duration of an investigation day, $T(n)$ is number of time durations of an investigation day, $C B L_{d, t}$ is a customer baseline load at $t$ hour on $d$ day, and $\operatorname{Load}_{d, t}$ is an electricity usage at $t$ hour on $d$ day.

$$
\sqrt{\frac{\sum_{d \in D, t \in T}\left(C B L_{d, t}-\text { Load }_{d, t}\right)^{2}}{D(n) \times T(n)}} \div \frac{\sum_{d \in D, t \in T} \text { Load }_{d, t}}{D(n) \times T(n)}
$$

$D(n)$ : Number of investigation days

$T$ : Time duration of investigation day

$T(n)$ : Number of time durations of investigation day

$C B L_{d, t}$ : Customer baseline load at $t$ hour on $d$ day

Load $_{d, t}$ : Electricity usage at $t$ hour on $d$ day

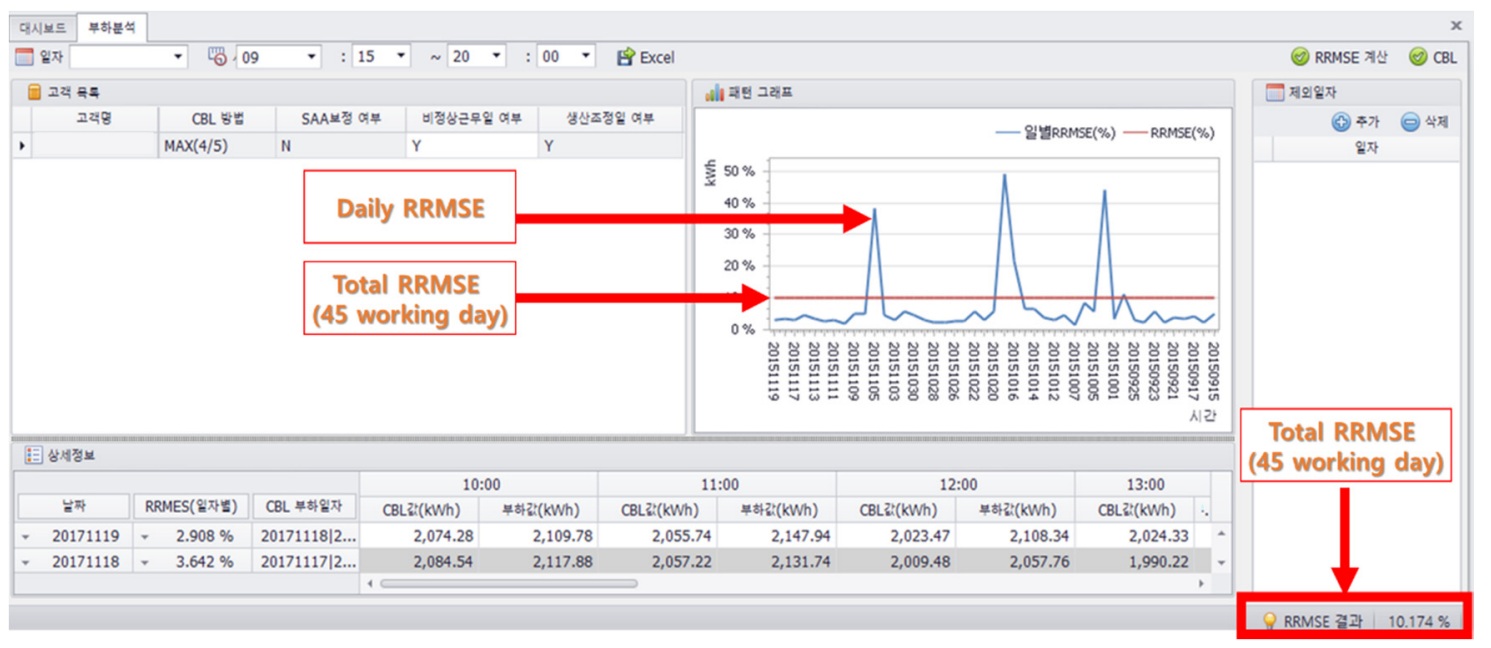

Figure 5. Relative root mean squared error (RRMSE) for a customer.

The RRMSE is calculated by dividing the RMSE (root mean square error) with the average value of electricity usage data. The fluctuation between the CBL and actual electricity usage is a critical judgment criterion as a reliable DR resource. To register as a DR resource in the Korea electricity market, the RRMSE value must be less than $30 \%$; if the value exceeds $30 \%$, it is not allowed to join the DR market. If the RRMSE value becomes more increased, conformity of power usage pattern decreases, which makes it difficult to judge the reduction value accurately. Although the U.S. PJM 
power DR market is set at less than $20 \%$, the Korea DR market is set to within $30 \%$ at the beginning of the system. To determine the suitability of the DR customer, the KPX enforces an annual RRMSE assessment, and then that result determines whether the DR customer can participate in the DR market for one year. This calculation is based on data from 45 weekdays from the date of verification [26]. For example, the flat line of the electricity usage graph in Figure 5 indicates 10\%, that means Figure 5 is a reliable DR resource, and therefore this customer can participate in the DR market.

The incentive for participating in the DR market can be classified into basic settlement and performance settlement, and the monthly basic settlement payment is as shown in Table 4. According to the reduction duration time, the actual performance-settlement payment is different under the KPX condition [27].

Table 4. Monthly basic settlement payment 2016-2018.

\begin{tabular}{|c|c|c|}
\hline Month & Basic Settlement Payment [KRW/kW] & Weekday \\
\hline 2016.12 & 5186.22 & 22 \\
\hline 2017.01 & 4994.68 & 20 \\
\hline 2017.02 & 4475.45 & 20 \\
\hline 2017.03 & 3767.84 & 22 \\
\hline 2017.04 & 1462.24 & 20 \\
\hline 2017.05 & 1335.86 & 20 \\
\hline 2017.06 & 3858.63 & 21 \\
\hline 2017.07 & 5395.95 & 21 \\
\hline 2017.08 & 4930.56 & 22 \\
\hline 2017.09 & 3694.44 & 21 \\
\hline 2017.10 & 1213.57 & 17 \\
\hline 2017.11 & 2919.16 & 22 \\
\hline 2017.12 & $4,697.14$ & 19 \\
\hline 2018.01 & $5,763.12$ & 22 \\
\hline 2018.02 & $4,249.36$ & 18 \\
\hline 2018.03 & $3,519.93$ & 21 \\
\hline 2018.04 & $1,245.46$ & 21 \\
\hline 2018.05 & $1,036.46$ & 21 \\
\hline 2018.06 & $3,300.72$ & 19 \\
\hline 2018.07 & $5,803.64$ & 22 \\
\hline 2018.08 & $5,354.86$ & 22 \\
\hline 2018.09 & $3,150.83$ & 17 \\
\hline 2018.10 & $1,003.48$ & 21 \\
\hline 2018.11 & $2,717.80$ & 22 \\
\hline Total & $85,077,404$ & 493 \\
\hline
\end{tabular}


To calculate the basic settlement money, Equations in (2) are applied to the integrated demand-side management solution [26].

$$
\begin{gathered}
\mathrm{DRBP}_{i . m}=\mathrm{ORC}_{i . m} \times \mathrm{BP}_{m} \times 1,000 \\
\mathrm{IBPC}_{i . m}=\frac{\mathrm{TDRBP}_{i}}{\mathrm{ORC}_{i . m} \times \mathrm{MRT}} \times \sum_{t}^{m} D R D_{i . t} \times 2 \times D F_{i, t} \\
\mathrm{DRD}_{i . t}=\operatorname{Max}\left(R S O_{i, t} \times 0.97-D R_{i, t}, 0\right) \\
\mathrm{BPC}_{i . m}=\operatorname{Min}\left(\mathrm{DRBP}_{i . m}, \mathrm{IBPC}_{i . m}\right) \\
\mathrm{FDRBP}_{i . m}=\mathrm{DRBP}_{i . m}-\mathrm{BPC}_{i . m}
\end{gathered}
$$

$D R B P_{i . m}$ Demand response basic payment by monthly (KRW)

$O R C_{i . m}$ Obligation reduction capacity (MW)

$B P_{m}$ Basic price by monthly (KRW/kW)

$I B P C_{i . m}$ Initial basic penalty charge (KRW)

$T D R B P_{i}$ Total basic settlement money during the contract period (KRW)

$M R T$ Maximum reduction time (Max $60 \mathrm{~h}$ )

$D R D_{i . t}$ Dispatch reduction deficiency $(\mathrm{kWh})$

$R S O_{i, t}$ Reduction ordered by system operator (MWh)

$D R_{i, t}$ Dispatched reduction $(\mathrm{kWh})$

$D F_{i, t}$ Dispatch flag (1 for active, 0 for non-active)

$B P C_{i . m}$ Basic penalty charge by monthly (KRW)

$F D R B P_{i . m}$ Final demand response basic payment by monthly (KRW)

To verify the DSMS functional test, the sampled data is divided into the following three categories: (1) large amount, (2) medium amount, and (3) small amount. Table 5 shows sampled data.

Table 5. The data for functional verification of demand-side management solution (DSMS).

\begin{tabular}{cccc}
\hline Amount & Large & Medium & Small \\
\hline Name & N Company & Provincial Government & G store \\
\hline Type & Factory & Building & Retail \\
\hline Peak $(\mathrm{kW})$ & 24,561 & 2002 & 57 \\
\hline Average power consumption $(\mathrm{kW})$ & 22,306 & 1534 & 52 \\
\hline Contracted capacity $(\mathrm{kW})$ & 10,000 & 1000 & 40 \\
\hline
\end{tabular}

Baseline load, peak, average power consumption, and CBL are calculated based on the customer's power usage which is monitored and recorded from an electricity smart meter. Figures 6-8 show the data on 26 June 2017. The large amount, $\mathrm{N}$ company, is a chemical company located in the southwestern area of South Korea. The power consumption pattern of $\mathrm{N}$ company is a typical factory type. Figure 6 illustrates the power consumption pattern baseline load and peak. The medium amount, a provincial government building, is located in the central area of South Korea. The CBL of this customer is 1938.56 kW at 13:00 14:00 on 26 June 2017, as shown in Figure 7. Lastly, the small amount, G store, is a retail store located in the southeastern area of South Korea. Figure 8 shows the RRMSE value as $9.815 \%$, less than $30 \%$. 


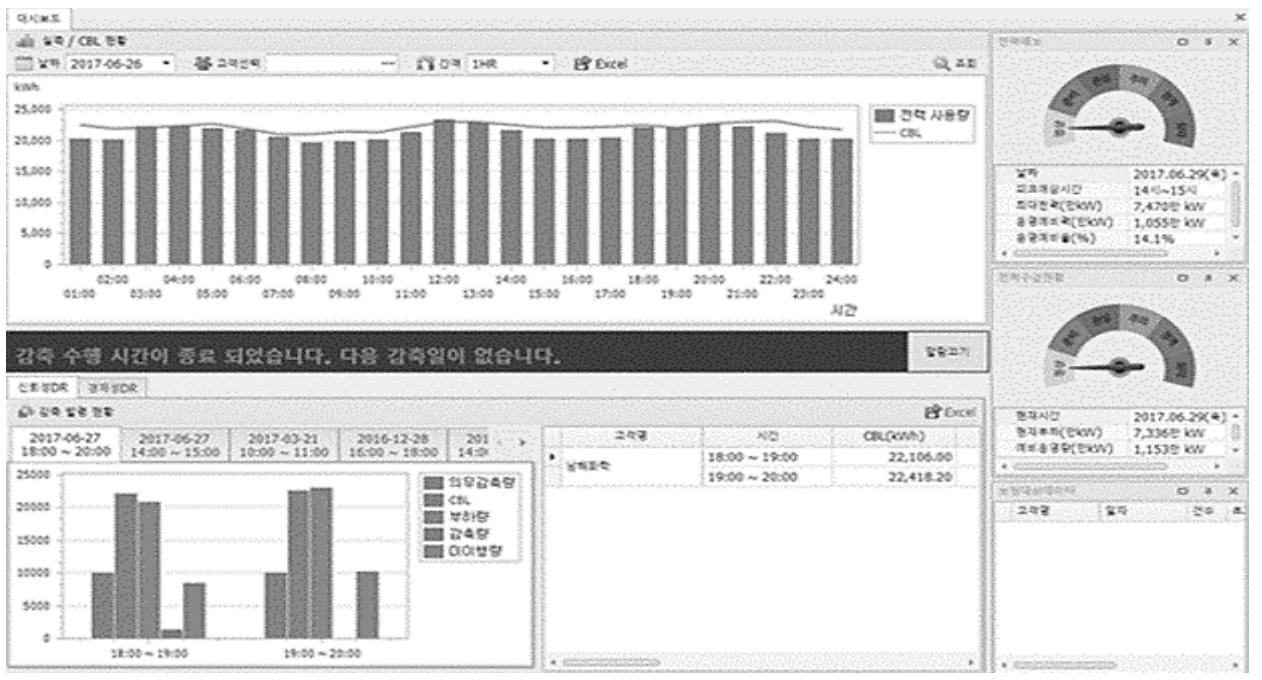

Figure 6. N company power consumption and baseline load.

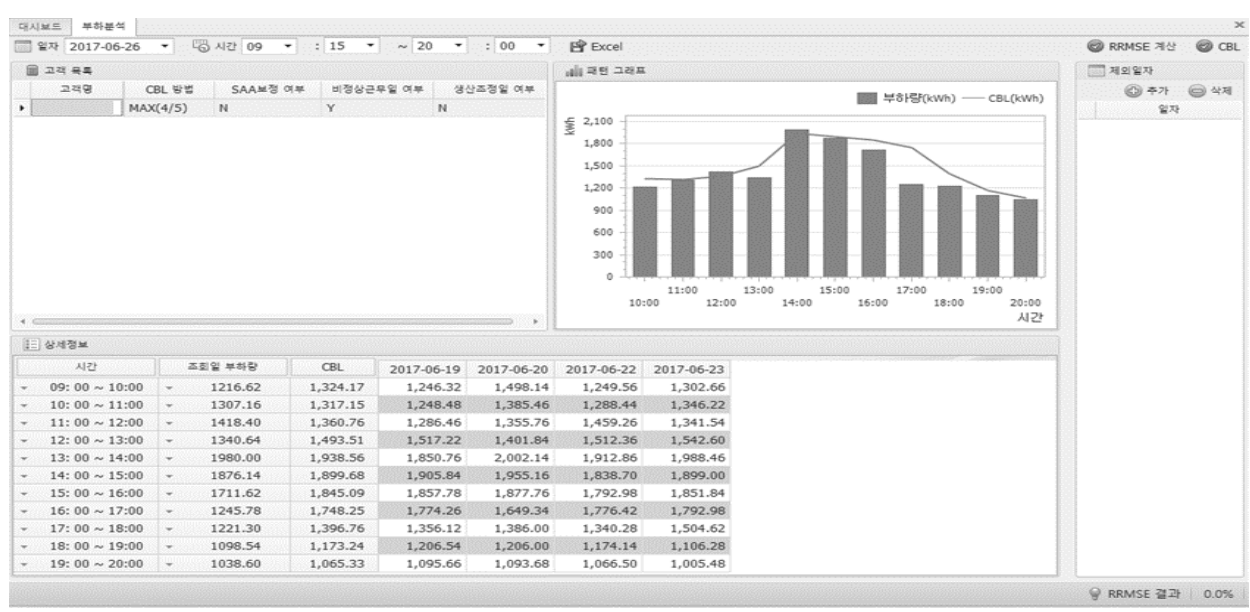

Figure 7. Provincial government building CBL calculation.

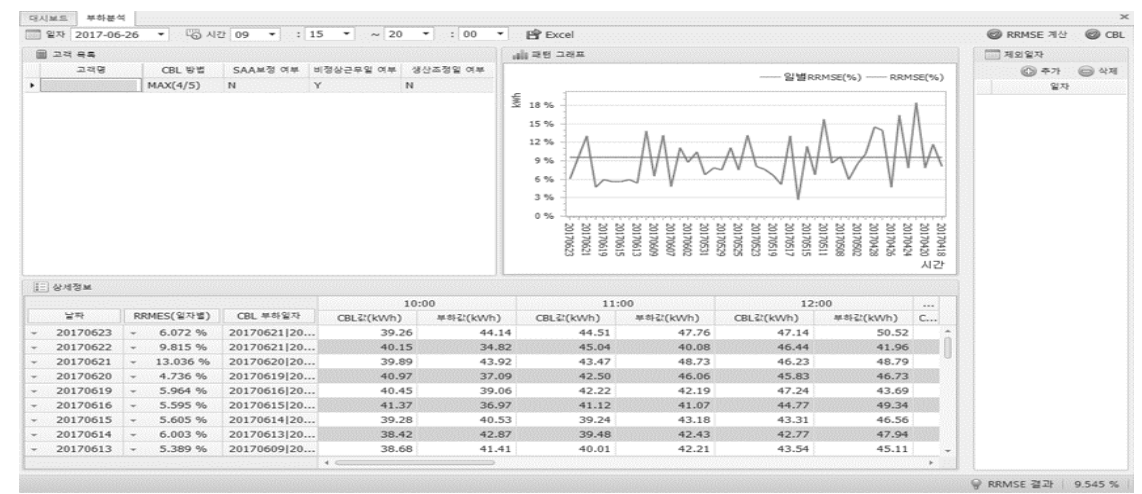

Figure 8. G store power RRMSE. 


\section{Results}

Table 6 shows the DR benefit and reduction rate results for three contracted customers after participating in the DR program. The results show the money-saving and energy conservation using the DSMS. The data used in this paper was collected in two years (from December 2016 to November 2018) from selected customers in South Korea. The N company case is selected to demonstrate the result. In the case of $\mathrm{N}$ company, the contracted capacity is $10 \mathrm{MW}$, participating in the $20 \mathrm{~h}$ DR dispatch during the two years. As a result, the DR delivery rate which is an average $108.03 \%$ and the benefit from the DR participation which is $854,900,394$ KRW (basic settlement benefit is $844,014,870 \mathrm{KRW}$ and actual settlement money is $10,885,524 \mathrm{KRW}$ ) are occurring, and the savings in electricity cost over the two years is about 2,160,560 KRW

Table 6. Participation result of annual demand response market.

\begin{tabular}{|c|c|c|c|c|c|}
\hline \multicolumn{3}{|c|}{ Name } & \multicolumn{3}{|c|}{ N Company } \\
\hline Month & $\begin{array}{l}\text { Reduction } \\
\text { Order }\end{array}$ & $\begin{array}{c}\text { Reduction } \\
\text { Duration Time }\end{array}$ & $\begin{array}{l}\text { Basic-Settlement } \\
\text { Benefit [KRW] }\end{array}$ & $\begin{array}{l}\text { Performance-Settlement } \\
\text { Benefit }[K R W]\end{array}$ & $\begin{array}{l}\text { DR Delivery } \\
\text { Rate [\%] }\end{array}$ \\
\hline 2016.12 & $\mathrm{O}$ & $2 \mathrm{~h}$ & $51,862,200$ & $2,224,080$ & $121.65 \%$ \\
\hline 2017.01 & $x$ & - & $49,946,800$ & - & - \\
\hline 2017.02 & $x$ & - & $44,754,500$ & - & - \\
\hline 2017.03 & $\mathrm{O}$ & $1 \mathrm{~h}$ & $37,678,400$ & $1,129,080$ & $121.44 \%$ \\
\hline 2017.04 & $x$ & - & $14,622,400$ & - & - \\
\hline 2017.05 & $x$ & - & $13,358,600$ & - & - \\
\hline 2017.06 & $x$ & - & $38,586,300$ & - & - \\
\hline 2017.07 & $\mathrm{O}$ & $3 \mathrm{~h}$ & $53,221,870$ & $2,429,646$ & $95.30 \%$ \\
\hline 2017.08 & $x$ & - & $49,305,600$ & - & - \\
\hline 2017.09 & $x$ & - & $36,944,400$ & - & - \\
\hline 2017.10 & $x$ & - & $11,421,800$ & - & - \\
\hline 2017.11 & $\mathrm{O}$ & $1 \mathrm{~h}$ & $23,884,000$ & 878,970 & $105.14 \%$ \\
\hline 2017.12 & $x$ & - & $46,971,400$ & - & - \\
\hline 2018.01 & $\mathrm{O}$ & $9 \mathrm{~h}$ & $57,631,200$ & $1,056,280$ & $108.17 \%$ \\
\hline 2018.02 & $\mathrm{O}$ & $1 \mathrm{~h}$ & $42,493,600$ & $1,094,716$ & $114.69 \%$ \\
\hline 2018.03 & $x$ & - & $35,199,300$ & - & - \\
\hline 2018.04 & $x$ & - & $12,454,600$ & - & - \\
\hline 2018.05 & $x$ & - & $10,364,600$ & - & - \\
\hline 2018.06 & $\mathrm{O}$ & $2 \mathrm{~h}$ & $33,007,200$ & 993,782 & $106.06 \%$ \\
\hline 2018.07 & $x$ & - & $58,036,400$ & - & - \\
\hline 2018.08 & $x$ & - & $53,548,600$ & - & - \\
\hline 2018.09 & $\mathrm{O}$ & $1 \mathrm{~h}$ & $31,508,300$ & $1,078,970$ & $104.44 \%$ \\
\hline 2018.10 & $x$ & - & $10,034,800$ & - & - \\
\hline 2018.11 & $x$ & - & $27,178,000$ & - & - \\
\hline \multicolumn{3}{|c|}{ Total } & $844,014,870$ & $10,885,524$ & - \\
\hline \multicolumn{3}{|c|}{ Name } & \multicolumn{3}{|c|}{ Provincial Government } \\
\hline 2016.12 & $\mathrm{O}$ & $2 \mathrm{~h}$ & $5,186,220$ & 211,700 & $114.32 \%$ \\
\hline 2017.01 & $x$ & - & $4,994,680$ & - & - \\
\hline 2017.02 & $x$ & - & $4,475,450$ & - & - \\
\hline 2017.03 & $\mathrm{O}$ & $1 \mathrm{~h}$ & $3,767,840$ & 99,475 & $105.72 \%$ \\
\hline 2017.04 & $x$ & - & $1,462,240$ & - & - \\
\hline 2017.05 & $x$ & - & $1,335,860$ & - & - \\
\hline
\end{tabular}


Table 6. Cont.

\begin{tabular}{|c|c|c|c|c|c|}
\hline \multicolumn{3}{|c|}{ Name } & \multicolumn{3}{|c|}{ Provincial Government } \\
\hline 2017.06 & $x$ & - & $3,858,630$ & - & - \\
\hline 2017.07 & $\mathrm{O}$ & $3 \mathrm{~h}$ & $5,395,950$ & 336,334 & $127.28 \%$ \\
\hline 2017.08 & $x$ & - & $4,930,560$ & - & - \\
\hline 2017.09 & $\mathrm{x}$ & - & $3,694,440$ & - & - \\
\hline 2017.10 & $\mathrm{x}$ & - & $1,142,180$ & - & - \\
\hline 2017.11 & $\mathrm{O}$ & $1 \mathrm{~h}$ & $2,305,028$ & 76,229 & $91.24 \%$ \\
\hline 2017.12 & $x$ & - & $4,697,140$ & - & - \\
\hline 2018.01 & $\mathrm{O}$ & $9 \mathrm{~h}$ & $5,763,120$ & 119,026 & $121.89 \%$ \\
\hline 2018.02 & $\mathrm{O}$ & $1 \mathrm{~h}$ & $4,249,360$ & 131,721 & $138.00 \%$ \\
\hline 2018.03 & $x$ & - & $3,519,930$ & - & - \\
\hline 2018.04 & $x$ & - & $1,245,460$ & - & - \\
\hline 2018.05 & $x$ & - & $1,036,460$ & - & - \\
\hline 2018.06 & $\mathrm{O}$ & $2 \mathrm{~h}$ & $3,300,720$ & 106,706 & $113.88 \%$ \\
\hline 2018.07 & $x$ & - & $5,803,640$ & - & - \\
\hline 2018.08 & $x$ & - & $5,354,860$ & - & - \\
\hline 2018.09 & $\mathrm{O}$ & $1 \mathrm{~h}$ & $3,150,830$ & 120,557 & $116.69 \%$ \\
\hline 2018.10 & $x$ & - & $1,003,480$ & - & - \\
\hline 2018.11 & $x$ & - & $2,717,800$ & - & - \\
\hline \multicolumn{3}{|c|}{ Total } & $84,391,878$ & $1,201,747$ & - \\
\hline \multicolumn{3}{|c|}{ Name } & \multicolumn{3}{|c|}{ G Store } \\
\hline 2016.12 & $\mathrm{O}$ & $2 \mathrm{~h}$ & 610,614 & 21,309 & $95.73 \%$ \\
\hline 2017.01 & $x$ & - & 599,362 & - & - \\
\hline 2017.02 & $x$ & - & 537,054 & - & - \\
\hline 2017.03 & $\mathrm{O}$ & $1 \mathrm{~h}$ & 446,284 & 10,547 & $93.41 \%$ \\
\hline 2017.04 & $x$ & - & 175,469 & - & - \\
\hline 2017.05 & $x$ & - & 160,303 & - & - \\
\hline 2017.06 & $X$ & - & 463,036 & - & - \\
\hline 2017.07 & $\mathrm{O}$ & $3 \mathrm{~h}$ & 647,514 & 36,711 & $170.65 \%$ \\
\hline 2017.08 & $x$ & - & 591,667 & - & - \\
\hline 2017.09 & $x$ & - & 443,333 & - & - \\
\hline 2017.10 & $x$ & - & 137,062 & - & - \\
\hline 2017.11 & $\mathrm{O}$ & $1 \mathrm{~h}$ & 262,012 & 8,323 & $82.96 \%$ \\
\hline 2017.12 & $x$ & - & 610,614 & - & - \\
\hline 2018.01 & $\mathrm{O}$ & $9 \mathrm{~h}$ & 599,362 & 11,935 & $122.22 \%$ \\
\hline 2018.02 & $\mathrm{O}$ & $1 \mathrm{~h}$ & 537,054 & 10,158 & $106.42 \%$ \\
\hline 2018.03 & $x$ & - & 446,284 & - & - \\
\hline 2018.04 & $x$ & - & 175,469 & - & - \\
\hline 2018.05 & $x$ & - & 160,303 & - & - \\
\hline 2018.06 & $\mathrm{O}$ & $2 \mathrm{~h}$ & 463,036 & 10,515 & $112.22 \%$ \\
\hline 2018.07 & $x$ & - & 647,514 & - & - \\
\hline 2018.08 & $x$ & - & 591,667 & - & - \\
\hline 2018.09 & $\mathrm{O}$ & $1 \mathrm{~h}$ & 443,333 & 10,113 & $97.89 \%$ \\
\hline 2018.10 & $x$ & - & 137,062 & - & - \\
\hline 2018.11 & $x$ & - & 262,012 & - & - \\
\hline & & & $10,147,42$ & 119,611 & - \\
\hline
\end{tabular}


To verify the capacity of the demand response from the customer, the request from KPX on 20 July 2017, 14:00 17:00, is displayed in Table 7. The large customer, $\mathrm{N}$ company, a big factory which has a contracted capacity of $10,000 \mathrm{~kW}$ delivered $97 \%, 93 \%$, and $96 \%$ for each period and the average delivery rate was $95 \%$. Figure 9 Illustrates the CBL load, the DR reduction result, and the delivery rate of each period. For example, Figure 9 a shows the CBL is $18,059 \mathrm{~kW}$, the real load is $8378 \mathrm{~kW}$, the DR reduction is $9,681 \mathrm{~kW}$, and the contracted capacity is 10,000 $\mathrm{kW}$ at 14:00 15:00.

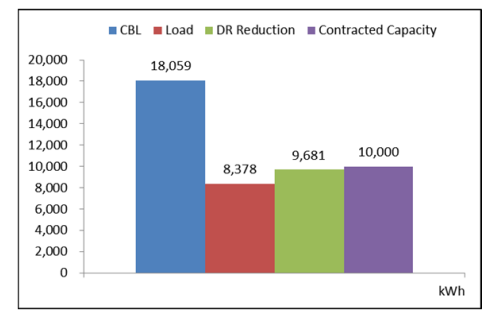

(a)

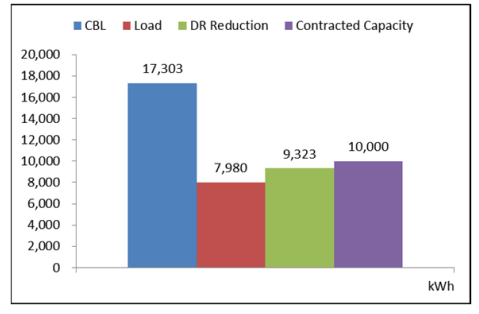

(b)

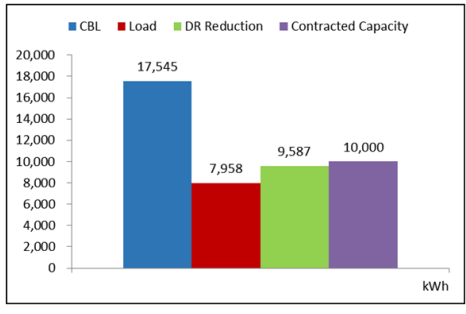

(c)

Figure 9. N company demand response result (data of 20 July 2017, 14:00 17:00).

Table 7. Result of demand response from customer.

\begin{tabular}{|c|c|c|c|c|}
\hline \multicolumn{2}{|c|}{ Amount } & Large & Medium & Small \\
\hline \multicolumn{2}{|c|}{ Name } & N Company & $\begin{array}{c}\text { Provincial } \\
\text { Government }\end{array}$ & G Store \\
\hline \multicolumn{2}{|c|}{ Type } & Factory & Building & Retail \\
\hline \multicolumn{2}{|c|}{ Contracted capacity $(\mathrm{kW})$} & 10,000 & 1000 & 120 \\
\hline \multirow{3}{*}{ CBL $(\mathrm{kW})$} & 14:00 15:00 & 18,059 & 1944 & 356 \\
\hline & 15:00 16:00 & 17,303 & 1904 & 349 \\
\hline & 16:00 17:00 & 17,545 & 1882 & 302 \\
\hline \multirow{3}{*}{ Real load (kW) } & 14:00 15:00 & 8378 & 669 & 158 \\
\hline & 15:00 16:00 & 7980 & 634 & 121 \\
\hline & 16:00 17:00 & 7958 & 470 & 113 \\
\hline \multirow{3}{*}{$\begin{array}{l}\text { DR reduction result } \\
\qquad(\mathrm{kW})\end{array}$} & $14: 00 \sim 15: 00$ & 9681 & 1275 & 198 \\
\hline & $15: 00 \sim 16: 00$ & 9323 & 1270 & 227 \\
\hline & 16:00 17:00 & 9587 & 1412 & 189 \\
\hline \multirow{3}{*}{$\begin{array}{l}\text { DR delivery rate } \\
(\%)\end{array}$} & 14:00 15:00 & $97 \%$ & $128 \%$ & $165 \%$ \\
\hline & 15:00 16:00 & $93 \%$ & $127 \%$ & $189 \%$ \\
\hline & $16: 00 \sim 17: 00$ & $96 \%$ & $141 \%$ & $158 \%$ \\
\hline
\end{tabular}

\section{Discussion}

Unlike the traditional energy management models that focus on the supply side, the DSMS considers the energy demand and control on the interactions between customers and supplier to manage electricity usage reduction and money saving. Through the implementation of the DSMS technology, the end user can automatically check necessary information, such as the CBL, the RRMSE value, and the amount of DR reduction, without the need for complex formulas and contents. Furthermore, the CBL and current usage can be checked in real time by monitoring power usage every $5 \mathrm{~min}$. The DSMS operated in the actual South Korea DR market for a year and based on these results the developed solution was verified. In addition, the result illustrates that the integrated demand-side management solution contributes by participating in the DR market and provides a benefit and satisfaction to the consumer. 
The researcher and stakeholders of the DR market should consider the criteria value of the RRMSE. As previously mentioned in Section 2, the U.S. PJM power suggests a RRMSE value less than $20 \%$, but the South Korea DR market sets the value within 30\%. This consideration helps an effective DR operation and derives a successful outcome. This unique demand-side manage experience in South Korea could provide the rest of the world with a model to efficiently maintain a national power grid and potentially suggest the development of novel energy managing plans for local situations and policy.

\section{Conclusions}

In this paper, a case study of the demand-side management solution in South Korea is introduced and explained. The experience from the consumer and the DR aggregator shows that the integrated demand response solution technologies is a fast-responding approach in a cost-effective way. The curtailed energy from contracted customers contributed by reducing peak power in the national power grid and therefore can effectively provide a reliable power system. The demand resource can be an alternative to the redundant generation in short term such as $5 \mathrm{~min}$. The case of a $10 \mathrm{MW}$ contracted customer shows average 108.03\% delivery rate and the total benefit of 854,900,394 KRW for two years. It also shows that all customers regardless of the amount of participation have responded well to 20-h DR dispatch during the two years. The results illustrate that the integrated demand-side management solution contributes by participating in the DR market and gives a benefit and satisfaction to the consumer.

Author Contributions: Methodology, W.K. and H.V.; software, H.-J.C. and S.-H.S.; validation, W.K. and H.-J.C.; formal analysis, S.-H.S.; investigation, W.K. and H.V.; resources, W.K., and H.-J.C.; data curation, W.K., and H.-J.C.; writing - original draft preparation, W.K., and H.-J.C.; writing—review and editing, W.K., and H.-J.C.; visualization, H.-J.C.; supervision, W.K. All authors have read and agreed to the published version of the manuscript.

Funding: The authors extend their appreciation to the Deanship of Scientific Research at King Saud University for funding this work through research group no. (RG-1439-028).

Conflicts of Interest: The authors declare no conflict of interest.

\section{References}

1. Rahimi, F.; Ipakchi, A. Demand Response as a Market Resource under the Smart Grid Paradigm. IEEE Trans. Smart Grid 2010, 1, 82-88. [CrossRef]

2. Vos, A. Effective business models for demand response under the smart grid paradigm. In Proceedings of the IEEE PES Power Systems Conference and Exposition PES 09, Seattle, WA, USA, 15-18 March 2009; Volume 1, p. 1.

3. USDOE. Benefits of Demand Response in Electricity Markets and Recommendations for Achieving Them. In Report to the United State Congress Pursuant to the Section 1252 of the Energy Policy Act of 2005; United State Department of Energy (USDOE): Washington, DC, USA, 2006.

4. Kim, J.; Nam, Y.; Hahn, T.; Hong, J. Demand Response Program Implementation Practices in Korea. In Proceedings of the 18th IFAC World Congress, Milano, Italy, 28 August-2 September 2011; pp. 3704-3707.

5. Lee, G.; Hong, W. A Study on the Adopting Decentralized Energy Supplying System in Urban Area. Archit. Inst. Korea 2007, 23, 239-246.

6. Rhee, C.; Park, J. Demand Resource Policy and Program Design for Electricity Market in Korea. In Proceedings of the ACEEE Summer Study on Energy Efficiency in Industry, Buffalo, NY, USA, 4-6 August 2015.

7. Won, J.-R.; Song, K.-B. An Analysis on Power Demand Reduction Effects of Demand Response Systems in the Smart Grid Environment in Korea. J. Electr. Eng. Technol. 2013, 8, 1296-1304. [CrossRef]

8. IEEE Guide for the Benefit Evaluation of Electric Power Grid Customer Demand Response. In IEEE Standards 2030.6-2016; IEEE: New York, NY, USA, 2016; pp. 1-42.

9. Zhang, Y.; Chen, W.; Xu, R.; Black, J. A Cluster-Based Method for Calculating Baselines for Residential Loads. IEEE Trans. Smart Grid 2016, 7, 2368-2377. [CrossRef]

10. Albadi, M.H.; El-Saadany, E.F. Demand Response in electricity markets: An Overview. In Proceedings of the IEEE Power Engineering Society General Meeting, Tampa, FL, USA, $24-28$ June 2007; pp. 1-5. 
11. Conejo, A.J.; Morales, J.M. Real-time demand response model. IEEE Trans. Smart Grid 2010, 1, $236-242$. [CrossRef]

12. Wang, Z.; Raman, P. An Evaluation of Electric Vehicle Penetration under Demand Response in a Multi-Agent Based Simulation. In Proceedings of the 2014 IEEE Electrical Power and Energy Conference (EPEC), Calgary, AB, Canada, 12-14 November 2014.

13. Zhang, C.; Xu, Y.; Dong, Z.; Wong, K.P. Robust Coordination of Distributed Generation and Price-Based Demand Response in Microgrids. IEEE Trans. Smart Grid 2017, 9, 4236-4247. [CrossRef]

14. Minchala-avila, L.I.; Armijos, J.; Pesántez, D.; Zhang, Y. Design and Implementation of a Smart Meter with Demand Response Capabilities. Energy Procedia 2016, 103, 195-200. [CrossRef]

15. Sachdev, R.S.; Singh, O. Consumer's Demand Response to Dynamic Pricing of Electricity in a Smart Grid. In Proceedings of the 2016 International Conference on Control, Computing, Communication and Materials (ICCCCM), Allahbad, India, 21-22 October 2016.

16. Vanderkley, T.S.; Negash, A.I.; Kirschen, D.S. Analysis of Dynamic Retail Electricity Rates and Domestic Demand Response Programs. In Proceedings of the 2014 IEEE Conference on Technologies for Sustainability (SusTech), Portland, OR, USA, 24-26 July 2014; pp. 172-177.

17. Gadham, K.R.; Ghose, T. Design of Incentive Price for Voluntary Demand Response Programs Using Fuzzy System. In Proceedings of the International Conference on Electrical Power and Energy Systems (ICEPES), Bhopal, India, 14-16 December 2016; pp. 363-367.

18. Khezeli, K.; Bitar, E. Risk-Sensitive Learning and Pricing for Demand Response. IEEE Trans. Smart Grid 2017, 9, 6000-6007. [CrossRef]

19. Schachter, J.A.; Mancarella, P.; Moriarty, J.; Shaw, R. Flexible Investment under Uncertainty in Smart Distribution Networks with Demand Side Response: Assessment Framework and Practical Implementation. Energy Policy 2016, 97, 439-449. [CrossRef]

20. Sarris, T.; Messini, G.; Hatziargyriou, N. Residential demand response with low cost smart load controllers Mediterr. In Proceedings of the Mediterranean Conference on Power Generation, Transmission, Distribution and Energy Conversion (MedPower 2016), Belgrade, Serbia, 6-9 November 2016.

21. Jain, M.; Chandan, V.; Minou, M.; Thanos, G.; Wijaya, T.K.; Lindt, A.; Gylling, A. Methodologies for Effective Demand Response Messaging. In Proceedings of the 2015 IEEE International Conference on Smart Grid Communications (SmartGridComm), Miami, FL, USA, 2-5 November 2015; pp. 453-458.

22. Wijaya, T.K.; Vasirani, M.; Villumsen, J.C.; Aberer, K. An Economic Analysis of Pervasive, Incentive-Based Demand Response. In Proceedings of the 2015 IEEE International Conference on Smart Grid Communications (SmartGridComm), Miami, FL, USA, 2-5 November 2015; pp. 331-337.

23. "Electricity Market Trends \& Analysis", Annual Report, KPX. Available online: http://www.kpx.or.kr/eng/ downloadBbsFile.do?atchmnflNo=23219 (accessed on 1 December 2018).

24. Lee, S.S.; Lee, H.C.; Yoo, T.H.; Noh, J.W.; Na, Y.J.; Park, J.K.; Yoon, Y.T. Demand Response Prospects in the South Korean Power System. In Proceedings of the IEEE PES General Meeting, Providence, RI, USA, 25-29 July 2010.

25. LEEa, Seungman. “COMPARING METHODS FOR CUSTOMER BASELINE LOAD ESTIMATION FOR RESIDENTIAL DEMAND RESPONSE IN SOUTH KOREA AND FRANCE: PREDICTIVE POWER AND POLICY IMPLICATIONS". 2019. Available online: https://www.researchgate.net/publication/337948056_ Comparing_Methods_for_Customer_Baseline_Load_Estimation_for_Residential_Demand_Response_in_ South_Korea_and_France_Predictive_Power_and_Policy_Implications (accessed on 1 March 2020).

26. Intelligent Demand Resource Market Operating Rules and Guideline; Korea Power Exchange: Jeollanam-do, Korea, 2016. (Printed in Korean)

27. Lee, J.; Yoo, S.; Kim, J.; Song, D.; Jeong, H. Improvements to the customer baseline load (CBL) using standard energy consumption considering energy efficiency and demand response. Energy 2018, 144, 1052-1063. [CrossRef]

(C) 2020 by the authors. Licensee MDPI, Basel, Switzerland. This article is an open access article distributed under the terms and conditions of the Creative Commons Attribution (CC BY) license (http://creativecommons.org/licenses/by/4.0/). 